The clinical governance of the soul: 'deep management' and the self-regulating subject in integrated community mental health teams

Social Science \& Medicine 56 (2003) 67-81

Brian Brown ${ }^{\mathrm{a},}$, , Paul Crawford ${ }^{\mathrm{b}}$

${ }^{\text {a}}$ Faculty of Health and Community Studies, De Montfort University, Milton Keynes MK7 6HP, UK

${ }^{\mathrm{b}}$ School of Nursing and Academic Division of Midwifery, Queens Medical Centre, The University of Nottingham, Nottingham NG7 2UH, UK

Abstract

Health professionals have often been described as if they were in conflict with the new managerialist spirit in health care. However, because of their distributed and mobile sites of intervention, the work of community teams presents particular problems for traditional notions of management. In this UK study we identify how mental health team members are regulated by means of a subtle 'deep management'. Team members point to a lack of management direction from senior colleagues, even though some of them participate in the management process themselves. However, the lack of overt management leads them to prioritise clients and foreground professional identities in performing their duties and much additional administrative work besides. This also meant that the organisational structure of the team was defined in subjective terms. Participants had become self-regulating 'deep managed' subjects under a largely hands-off management regime.

Keywords: Clinical governance; Self-regulation; Mental health; Community care; UK 


\section{The clinical governance of the soul: 'deep management' and the self-regulating subject in integrated community mental health teams}

\section{Introduction}

In this paper, we shall attempt to show how management is accomplished amongst a diverse set of mental health professionals who work in a community setting in the Midlands, UK. The work of community based mental health care teams presents special problems for management as the individuals often work on their own, away from offices and close supervision. Indeed, many of them do not share a common physical site and are housed in a variety of different parent organisations such as social service departments, hospitals, health authorities and GP practices. Whereas there is a good deal of scholarship which highlights the managerial role in health care settings, much of this has focused on hospitals (e.g. Traynor, 1996) or services and professionals based in GP fundholding practices (e.g. Tinsley \& Luck, 1998). Such scholarship has tended to focus on the attitudes of staff to management techniques, budgetary matters and patient care. It tends, for example to explore the debates, tensions and frictions between practitioner and managerial cultures, priorities and world-views.

At the same time, there is relatively little which explores the technologies of management and practitioner subjectivity when the work group and its physical disposition has no such integrity. Because of their manifold sites of operation and organisational location, the personnel in Integrated Mental Health Teams (IMHTs) represent a special case for studies of health care management.

Yet, what is remarkable is that despite the potential lack of coherence, their conduct - or at least their accounts of it - is curiously regular, familiar and predictable. To understand this regulation and orderliness in the field we have coined the term 'deep management' - management that goes on at a level which is subtler and more pervasive than the ordinary notions of direction and supervision associated with the term would imply.

In order to make sense of deep management it is first necessary to demystify one of the basic tenets of studies of health care professionals in their occupational habitat. Hitherto 
there has been some interest in how there is a line of fracture between practitioner and manager cultures. Traditionally, authors have highlighted the different priorities and working practices. Traynor (1996) convincingly documents the friction between nursing staff and managers. Wells (1997) distinguishes a 'street level bureaucracy' operated by practitioners which may operate differently to the intentions of policymakers and managers. The thrust of this work is that there exists a relative autonomy when it comes to clinical or professional decision making, which, in Wells's case, is seen as a relative no-go area for management. Indeed, managers may be motivated to avoid scrutinising the work of practitioners too closely so as to avoid responsibility in the event of complaints or scandals.

If we were to characterise the trend in the literature in slightly cruder terms, we could even go so far as to say that there is an image of practitioners as heroic pirates resourcefully bending the rules, 'struggling with complex and arcane service systems' (Onyett \& Ford, 1996) and creatively filling the void when external provision is absent or inadequate (Stein, 1992). Practitioners may be found using quaint yet effective folkways to evaluate patients and solve problems (Murdach, 1995) or fiercely defending their subcultural territory against managerial inroads (Syrett, Jones, \& Sercombe, 1997). The ideological split between managerial culture and the coalface of care can appear very deep indeed:

I feel hostile to business ideas being applied to services and vulnerable clients. People are not commodities. They are often fragile and vulnerable. They feel like they are being viewed like rows of biscuits on a Sainsbury's shelf. (Respondent quoted in Syrett et al., 1997, p. 163.)

It is our contention that this apparent split between the strata of management and practitioners has misled researchers and to some extent practitioners themselves to overemphasise their autonomy and to under-theorise the depth to which management and its 'governmental technology' (Rose, 1990) has penetrated everyday conceptions of working life for service providers.

To researchers and commentators, perhaps the plucky and independent Community Mental Health Nurses (CMHNs), Social Workers and allied professions have provided an attractive model. However, focusing on the relative independence and apparently 
resistive culture of health care practitioners draws our attention away from the more subtle ways in which the practitioner soul is governed (cf. Rose, 1990). Rose's phrase 'governing the soul' is apt, for as we shall argue, the locus of management is increasingly located inside the individual practitioner. Rose's perspective contains elements which were originally promoted by Foucault (e.g. 1977) and it is to these two authors we shall turn in order to grasp the disciplinary form of the community mental health team. The teams themselves were originally posited as a way of rationalising the delivery of care, yet most importantly this has enabled new forms of subjectivity to emerge within the organisation of the teams, which as we shall argue, tend to facilitate the manageability of team members through their very distance from the management process. Panoptic governance is not visible in a strong form through overt technologies of surveillance. Rather, following Rose (2000) we would argue that the training and working practices of health professionals facilitate the development of discursive and intrapsychic realms of self-knowledge and self-regulation. This revised Foucaldian challenge must be taken very seriously if we are to make sense of how management can work most effectively even when it appears to be invisible or ineffectual (McKinley \& Starkey, 1998; Hatchuel, 1999). As we shall see, management in the context of community health teams is not entirely about the rational tasks of resource distribution or task planning but is about developing subjectivities which are self-governing and self-tasking in the team and in the field.

At first glance this situation of community mental health teams (CMHTs) might seem a hard case for the approach we are advocating. The teamwork approach in the community has been described as being rife with interprofessional conflict, ambiguous and unfocused aims and ineffective leadership (Ovretveit, 1993; Kings Fund, 1997; Norman \& Peck, 1999). Thus, the pathways of power are not nearly so clear as between the guard and the prisoner in Bentham's or Foucault's original formulation. In addition, the idea that practitioners might regulate themselves in line with their professional identities could be untenable because these professional identities themselves are ambiguous. This is especially the case for nurses, whose struggles to professionalise are well-documented (Morrall, 1998; Patmore \& Weaver, 1991). 
In addition, there are some well-known arguments about the medical dominance found within health care such that medical staff are argued to have a controlling stake in the decision making, record keeping and governance of everyday patient care, even though much face to face contact is carried out by nurses in a 'handmaid' role (Berg, 1996;

Berg \& Bowker, 1997). This working practice has become sufficiently ritualised for some authors to call it the 'doctor-nurse game' (Stein, 1967; Snelgrove \& Hughes, 2000). It has been noted in community health (Griffiths, 1997; Tinsley \& Luck, 1998) as well as in hospital settings. Despite the cautions of those authors who have seen some 'fracturing of medical dominance' in psychiatry (Samson, 1995), the lines of influence here might still be relatively easy to detect amongst our informants.

These latter two points, about the difficulties over professional identity experienced by some groups in the health service, as well as the possibility of medical dominance make it perhaps less easy for individuals to become self-governing entities in the sense envisaged by Rose.

Nevertheless, the concept of the individual as a self-governing entity, responsible for his or her own education and development is central to a number of initiatives in the UK, such as lifelong learning (Piper, 2000), and, importantly for the health service, clinical governance which in the UK takes its cue from the seminal 'first-class service' (Department of Health, 1998) introduced as: 'A framework through which NHS [National Health Service] organisations are accountable for continuously improving the quality of their services, and safeguarding high standards of care, by creating an environment in which excellence in clinical care will flourish.' The means of achieving this had previously been outlined (Department of Health, 1997). First, there was to be a set of national standards, delivered through national service frameworks (Department of Health, 1999b) and the National Institute for Clinical Excellence. Second, the local delivery of quality services was to be undertaken via the mechanism of clinical governance and a statutory duty of quality and this was to be supported by lifelong learning programmes for staff, and professional self-regulation. Thirdly, services were to be monitored via the Commission for Health Improvement and an NHS performance framework. 
From our point of view, the significant aspect of clinical governance is the reliance on making individual practitioners responsible for developing their skills for accessing evidence, ensuring that practice is 'evidence based' and being responsible for their own professional development and implementation of quality standards (Department of Health, 1999a; NHS Executive, 1999a). In this context, a good deal of involvement of nursing staff, both individually and collectively, is encouraged (Castledine, 2000; Elcoat, 2000; Harvey, 1999). The new entrepreneurial, professional selves which are encouraged by these initiatives and backed by the UK's National Service Frameworks (Department of Health, 1999b, 2000) involve a refiguring of the private self too, in ways which might afford the clinical governance of the practitioners' souls more effectively. Thus, in the present study we shall aim to detect the extent to which participants are regulating themselves in the face of the reorganisation and potential for conflict which has been noted by other scholars of teamwork in community mental health.

The present study: method and participants

The data we shall discuss originate from a study of three interdisciplinary CMHTs in a semi-rural area in the Midlands (UK). The staff in question had until recently been working in single discipline teams (referred to as CMHTs), but a new structure had been developed so that each team was now interdisciplinary, such that they contained a variety of professions such as CMHNs, occupational therapists (OTs), clinical psychologists, psychiatrists and mental health support workers to form IMHTs. In the empirical work they were questioned about their working lives and organisational context by one of the authors (PC) as part of a comprehensive evaluation of the new way of working. The interviews included topics such as their feelings about the present way of working, how they fitted into the team at a professional and personal level, and how the working arrangements could be improved. At the time, PC was a relative newcomer to the area and was able to facilitate candour by the fact that his allegiances had not yet crystallized - it was relatively easy for him to distance himself from management issues and establish rapport with the informants.

The three teams had 11, 10 and 8 members, respectively. The teams each included a broad skill mix, involving expertise from psychiatrists, psychologists, OTs, social 
workers, CMHNs and mental health support workers. The CMHNs were numerically dominant, but each team also included all other occupational groups, though in smaller numbers. Their working practices were complicated by the fact that many of them carried over a caseload from their previous working arrangements, which was not necessarily shared with other team members, although efforts were being made to harmonise the caseloads and the catchment areas. Two teams had a highly distributed way of working, using offices in a variety of establishments, whereas many members of the third used facilities in what we shall call the resources centre (RC). However, despite the geographical differences, no systematic differences in the way the teams approached their work were apparent in the interview data, and all were subject to the same structure of management and regulation. The teams were managed by means of weekly meetings of team members, which were deliberately kept non-hierarchical, inasmuch as they used a 'rolling chair' method which involved them in taking turns to chair the meetings, which dealt with clinical and business matters. In addition, a steering group met periodically to manage the three teams. This consisted of a nominated team member from each team, senior managers from the local mental health trust and social services, as well as two senior managers from the local health authority.

The corpus of interview material in this paper derives from 29 interviews with diverse occupational groups across three teams. The topics covered in the interview were determined through discussion with a subset of practitioners formed into a research sub-group so that the interviews would reflect the practitioners' concerns. Following transcription, the corpus of material was examined via a close-reading by the two authors. Previously, the standard practice amongst scholars writing in the field of governmentality studies has been to read off the practices of government from the narratives of an organisation or social sphere in a fairly straightforward fashion (Moore \& Valverde, 2000; Novas \& Rose, 2000). However, our attempt here to identify the kind of professional identity and self-management process encouraged in this organisation deserves a more nuanced and rigorous methodology, and a theorisation of how we may link data from the participants with more governmental processes of organisational and self-regulation. 
Accordingly, the analytic strategy was informed by two major strands in qualitative analysis. First, the method parallels the approach of grounded theory (Glaser \& Strauss, 1967; Strauss \& Corbin, 1998). Here, theoretical developments are made in a bottom up manner such that they are anchored to the data. Thus, an initial intuition that we might find friction between practitioners and an interventionist management culture was not sustained on inspection of the data. Thus, we reconceptualised what the process of management involves for the team members, given that their conduct was still strongly focused on caring for patients. Our revised focus then involved a curiosity about how the management and self-government of our informants was accomplished in the absence of overt direction from senior colleagues. The strength of the grounded theory approach is illustrated by the way that previous authors' accounts of management in health work were challenged by the data. Much of the literature we reviewed earlier led us to expect the traditional antipathy between management and practitioner cultures, but we detected much counterintuitive evidence that more subtle processes of self-management or self-government were also a feature of their social action. Likewise, whereas much literature on health care has either focused on doctors themselves or has described how medical staff retain their power, as we shall see, the participants provided us with little evidence that direct lines of accountability lay between, say nurses and psychiatrists. Thus, we have sought to unravel the conundrum of how orderliness in the distributed workplace is maintained.

The second strand of our analytic strategy was to follow the lead of Potter, Edwards and colleagues (e.g. Edwards \& Potter, 1992; Speer \& Potter, 2000; Potter \& Wetherell, 1987) who argue that language - such as when people talk about professional identities and the like - is a form of social action. Rather than merely describing the state of the world, language is a transaction in which the actors try to perform some social business, for example forestalling counter claims, or using concepts such as caring, clients' interests or professional identity as a kind of rhetorical impression management. Thus, in the forthcoming presentation we will be attentive to how formulations of job roles and their responsibilities might for example justify actions, secure the speaker's identity as a caring professional or assign blame elsewhere. Thus, rather than transparently reflecting organisational structure, or the participants' thoughts and feelings, the 
discourse from participants represents a conversational construction of their working lives in which they are interested parties.

These two ways of approaching the data may at first seem contradictory - if language is a strategy for self-presentation it may not be easily read as a resource for deducing a form of governmentality. However, our interest is in how people describe the process of organisation, management and government and the usual cautions over self-report data must perforce be borne in mind when considering how their conduct in everyday working life relates to the interview discourse. However, there is a long tradition of interest in studying the nature of participants' discursive construction of issues in mental health and exploring the implications of this for the delivery of mental health care. Phil Brown (1990) documented how patients and staff collaborated to produce diagnoses using standard assessment questionnaires from which the staff maintained an ironic distanceF'some of the questions might seem silly'. Barrett and Good (1996) have shown how team members in hospital settings perform a kind of joint discursive work to achieve an understanding of their patients in terms of the diagnostic category 'schizophrenia'. Griffiths (1997) has shown how teams' collaborative construction of ideas about mental illness corresponded to decisions about which referrals they should deal with. A more restricted definition of mental illness was used by one of Griffiths's teams to regulate its workload, for example.

Whereas it is not possible to 'read off' the working practices in any simple way from team members' discourse, it is clearly accepted by a number of authors then that the discursive formulations of tasks, roles and clients' problems may be important in making sense of the interpersonal and organisational processes in health care. Indeed, given our contention later that much of what used to be a part of the organisation has been relocated into subjective territories of selfhood, these connections are worthy of discussion.

\section{Results and discussion}

Initially, we expected to find participants chafing against an interventionist management 
style. However, there was no such evidence in the interview data. This 'representation of absence' (Gervais, Merant, \& Penn, 1999) prompted a renewed examination of what participants oriented to when discussing management and social order at work.

\section{Steering clear of the steering group}

Practitioners' perceptions of the role of the steering group illustrated some fundamental issues in the management of service delivery. Although nominally constituted to manage their work, it did so with a very open brief which was not consolidated or codified in a way which appeared clear to practitioners or was represented in their discourse. At a practical level in the interviews participants expressed uncertainty about what it was for or what it did - even those who took part in the steering group meetings. Whereas formal policy on the issue may have existed at some level in the organisation, the overwhelming impression from the interviews was that day-to-day business was conducted in a fog of uncertainty. A non-member of the steering group put it this way:

$\mathrm{P}$ : I think that for me the steering group tends to be er a group of people, a mysterious group of people that er, that apparently have these meetings and then [name of clinical psychologist] comes and says well, this is what we discussed at the meeting (yeah). Erm, erm, it, it tends to be a bit far away from, from me (right) this steering group.

I:OK, yes.

$\mathrm{P}: \mathrm{I}$ think I should go to one of their meetings one day and see what the people are doing there. (CMHN)

Participants who also sat on the steering group were curiously similar in their comments, as if minimising or discounting their role in the process:

P: Well I went once and they erm, there was, there was erm. Why did I go? Oh yes, erm a colleague was on an annual leave that week, asked if l'd go in her place, to represent our Southern team (I: yes) and er l'm not sure how typical it was of the meeting, but they certainly can talk a lot of hot air (I: yes). A lot of waffle, and I came away thinking what a, no decisions were made (l: yes) and only to come back and I: [Were there no objectives set? 
$P$ : No there was nothing concrete at all, it was very fluffy.

I: And did you, did you gather, was there any, was there any improvement in that over time? Did you or, did you pick up anything from your last

$P:$ No

I: that you, was there an improvement after that one that you attended?

$\mathrm{P}:$ No, not really. (CMHN)

This participant is actively discounting (cf. Pestello, 1993) his involvement:only going once. Even though he was a participant in the team meeting he criticises the team as if its tendency to 'talk a lot of hot air' is something external or other than himself. This ability to distance oneself from the team and from managerial activity was a feature which was common in the interviews. There is an implicit professional ideology at work which helps to explain this, as described most compellingly by a social worker:

I: Mmm, there's um, you have a steering group as well don't you for your team?

$\mathrm{P}$ : [Now and then (mmm). No I try to steer clear, steer clear of (I: laughs) the steering group.

I: Er, I mean, what do you make of it?

$\mathrm{P}$ : Sorry?

I: What do you make of the steering group and what's its significance for you?

P: Erm, I can't really answer that because I've never really been to a steering group meeting, erm, no that's not technically true we had a training day I suppose and they were all there, erm I find it very, I'm not the best person at erm at meetings, erm, I always put myself down as a nuts and bolts man, you know, I'm, I want, where I should be is with the clients ( $\mathrm{mmm}$ ), not sitting on a committee somewhere rattling ( $\mathrm{mmm})$. So if they want to do it fine $(\mathrm{mmm})$, and if it affects me and I don't like it, then I've got access to the steering group because my boss is part of the steering group. I: Right.

In this formulation, which was echoed elsewhere in discussion with participants from a nursing, occupational therapy and social work background, the job of the caring professional is the work with clients rather than the management of the caring process. A corollary of this common theme was that attending meetings was seen as a burdensome activity of secondary importance to dealing with the clients themselves. The distress of clients or the demands they placed on care teams was mentioned as an 
understandable reason for absence from meetings.

Thus, we have an ordering of importance, where the meetings are hot air and the clients are the real, morally substantial and emotionally compelling part of the work. Rather than describing friction between management and practitioners, these participants formulate the situation as if there was a lack of management. Amongst social workers, CMHNs and OTs, the role of the steering group is minimised. According to the participants there is very little in the way of leadership, direction or conventional management emerging from the steering group. Conventional theories of management might stress the importance of thoroughgoing communication and participation (e.g. Mathis \& Jackson, 1994). Thus, this might appear as a failure of management. However, from Rose's perspective we can see this process as facilitating the internalisation of work discipline and professional conduct as it is on this that staff have to rely to achieve some sense of meaning and direction in their work (cf. Grey, 1994).

The apparent distance of the steering group was further reinforced by the sense that 'nothing concrete' was decided. As phrased by the 'nuts and bolts' man above, this appears to reinforce the sense that real work is not with management at all, but with clients. The ideology of caring, which some authors have described as disabling, might well be disenfranchising these participants from the management process but it is also aggrandising their own accounts of themselves as the people who carry the burden of care. Certainly, in the discourse analytic tradition established by Potter, this can be seen as impression management, yet it is one which has implications for the arguments advanced by Rose and other organisation theorists (e.g. Du Gay, 1997). It is a position which disenfranchises them from the management process.

This distance is enhanced by the very notion of caring itself. The ideology of 'caring' has been argued to be an important yet at the same time professionally disabling part of nurses identity (Garvin, 1997). Here, we see it being applied to a much more diverse group of professionals in the integrated community team including OTs and social workers. Whereas the presentation of the occupational self as a caring individual can be seen as a way of showing oneself in a positive light, it is nevertheless also a way in 
which participants are distancing themselves from the process of management. Here then is one component of the process by which the participants regulate themselves by means of this resonance they establish between their working lives and the ideology of caring, which has its origins in questions of occupational choice, professional training and socialisation, and even the satisfactions of caring itself.

The perceived distance and incompetence of the steering group was reinforced by a related feature, namely the perceived inability of the steering group to make decisions or allocate resources of the kind which would be noticeable in working with clients. For example, one issue the steering group was called upon to resolve was reallocating clients so that their geographical dispersion corresponded to the territories of the teams:

certain things were promised from the steering committee, and then weren't forthcoming, such as the locality mapping thing, you know they, they were going to take responsibility for doing that (yes). There was talk of somebody being employed to actually look at that. That hasn't been forthcoming and it's been thrown back to us, to er, to do that (CMHN).

The practitioners claimed that the steering group was not involved in this process in the way they had expected. Significantly, the team members described themselves as accommodating the administrative work which was needed. This theme appeared again in some other interviews:

for example there was a lot of talking about the fact that we needed an admin. person, and this was taken up to the steering group to discuss, but then when the answer came back that there was no money, they knew we had to just think well, what are we going to do next, as opposed to having been stuck still in the previous mode. (Clinical Psychologist)

There were also a number of specific accounts of expectations not being met, where a more managerial role on the part of the steering group was not forthcoming:

P: I don't think they've done anything. I don't think, I don't feel they're giving us the resources that they promised. Erm, and I haven't seen anything in the way of support from them. Erm and I think from the, the minutes of the last meeting that they had, one team was having problems which was minuted and the advice from the steering group was to go back to the decision making process. And I'm thinking it must have 
been important enough to bring to the attention of the steering group, then I think they should have dealt with it in a more supportive way.

I: So it was kind of folded back into the team?

P: Mmm. (CMHN)

Thus, in the formulations of its role presented by our participants, the steering group has two salient features. One is that it is remote from the everyday business of caring for patients, which is perceived to be more important anyway. The other is that it avoids dealing with the kinds of issues which are brought to its attention by the team members but leaves them for the teams to deal with themselves. Hence, they establish their logic for the accusation that the steering group talks 'a lot of hot air'.

From the point of view that managers are there to manage the activity of health care this might seem a little odd. Managerialist ideologies have been detected throughout health care by many scholars (e.g. Hicks, 1998; Traynor, 1996). Yet our informants construct the steering group as actively refusing the managerial imperative. This is at odds with the interventionist management style which was detected by Syrett et al. (1997) or Traynor (1996). Moreover, whilst the sense of disengagement individuals have from their working lives is addressed by Berger and Luckmann's (1966) concept of 'cool alternation', this does not capture the effortful contrivance of self-management which we shall see the practitioners performing in their accounts later.

\section{Deep management and self-regulation}

In order to explain the significance of this for the team members and their daily work, let us elaborate what we mean by the term 'deep management' and explain how the features which we have described so far make it more effective.

The day-to-day regulation of work activities is a variety of management activity which we shall call 'surface management' This might involve an assertive involvement in the work of lower level organisation members to assign tasks, to monitor, supervise and evaluate their work, or it might involve a facilitative process whereby managers provide the circumstances whereby their junior colleagues can flourish and excel. The ability of 
management cultures - especially those which place a stress on appraisal and career development - to impinge on the lives of organisation members is well-documented (Grey, 1994). The identity projects of staff under these regimes, where they appear to be enthusiastically dedicated to the organisation even when the work is dull and onerous, can be relatively clear-cut. This model of how management works is limited in its applicability to the present case however. There is no such manifest structure for regulation or into which the individual's identity can grow.

The case of people in CMHTs, then, can perhaps best be described as being governed by a form of 'deep management'. Deep management, by reflecting problems recursively onto the people who suffer from them, is able to individuate the concerns within the dissatisfied employees. Problems then become a question to be dealt with by individuals. Thus, team members describe themselves working longer and harder, taking more trouble with documentation, or spending longer in meetings:

I: have you found yourself doing anything extra?

$\mathrm{P}$ : Going to meetings.

I: Right, anything, anything else?

$\mathrm{P}$ : Trying to unravel the accommodation for the meetings.

I: Yes.

$\mathrm{P}:$ Going to the steering group meetings. Erm, keeping up the momentum of the closer contact with the colleagues in the meeting (I: $\mathrm{mmm})$, in the team as I've just illustrated, which was pretty close before. Rearranging my caseload so it fits this, I had to sit down and re-jig my whole caseload (I: $\mathrm{mmm}$ ). Closed cases and transferred cases, so that's extra work as well. (Social Worker)

If the steering group is described as doing nothing then the team members describe themselves as working harder to undertake the administrative work they see to be necessary. If additional staff are not appointed to do 'admin.' then the team members do it themselves over and above their normal duties. Team members bolstered their claims to be doing extra work by reference to the imperatives which are related to their caring professional identity:

I mean we have our own workload to do (right) and we can't erm, reduce our workload to accommodate meetings, I think that would be the wrong way round. 


\section{$(\mathrm{CMHN})$}

The team members then, especially the CMHNs, social workers and OTs tend to present work with clients as imperative, and something which should not be reduced or diluted. Thus, it was common to see them describing an increase in workload as a result of the new team structure:

I mean, the, the extra, I would say that I have to work harder to build up some of the relationships [with colleagues] (I:mmm), along the lines of what we were saying previously, erm, whereas that, that process was, was easier before. Erm, I mean the only other issue that I can see that would in any way add to my workload is kind is kind of chairing the meetings or, or taking the minutes. (Social Worker) This was especially true of the most imperative parts of the workload, the contact with clients:

being part of the, part of the team has certainly in, in, increased erm the amount of work l've got to do because the referrals come in more quickly. there's certainly more work involved yes, (right) yeah, without a doubt. But then again, if, if, it needs to be done you do it. (Social Worker)

The steering group is described as being remote from these professional imperatives and as not telling team members how to act. The workforce sees the increased labour with some resignation and claim to undertake it because of the virtue in seeing to clients needs. If they are indeed acting as they claim, they have effectively been 'deep managed' - become self-regulating workers without having to be told what to do. Whether consciously or not, by doing nothing, the steering group could be understood from Rose's perspective to have performed a masterful feat of management. It can effectively regulate the behaviour and consciousness of the employees without necessarily having to stipulate how they should act. They describe themselves as staying at work longer, seeing more clients and taking on additional duties in a way which would be very difficult to achieve if a sharply suited manager simply strode around and instructed them to do so. As Du Gay (1997, p. 341) says, this represents 'a more entrepreneurial, indirect form of government - or controlled decontrol - which relies for its effectiveness upon the self-regulating capacities of its employees as subjects'. The distance they feel from the steering group is an important part of this process. As Kunda (1991) documents, employees who have a cynical stance towards management 
ideologies are more easily governable. Their playful ironising of the culture of steering groups may undermine their ability to refuse to play out the professional scripts in which they are embedded.

The process of deep management is facilitated by its resonance with the professional ideology of caring and prioritising work with clients. It is also perhaps enhanced by the kinds of policy initiatives at a national level, such as the National Service Framework for Mental Health which emphasises the importance of foregrounding clients' needs and the value of timely, accessible and regular contact between clients and professionals. The idea that the steering group is effectively not doing anything is itself part of this process of deep management. The individuals are convinced of its distance and incompetence. Therefore they do the work of managing themselves. Their new duties, such as attending team meetings, which they have to chair and take minutes for themselves, and even find rooms to meet in, are undertaken remarkably willingly. Yet at no time do they say that they were instructed to do this by the steering group. The only stipulation was that the meetings should be weekly, rather than fortnightly as one team wished them to be. The individuals have governed themselves into these new activities, possibly because without them they could not undertake what they saw to be the important, caring part of their role. Whereas they did not formally orientate to government policy on mental health care, a sociologically minded analyst would be quick to identify the correspondence of their activity with the desiderata of the UK's National Service Framework too.

\section{The handmaid role?: searching for signs of medical dominance}

From the point of view that the teams may simply be reflecting well worn pathways of medical dominance, which has been detected in community mental health by Griffiths (1997) we examined the data to see whether there was evidence from either the psychiatrists that they supervised and directed the process of care, or from the other disciplines that they were taking their cue in an overt way from medicine. 
putting more into the process as a result of the new working arrangements and finding themselves inconvenienced:

From my personal point of view (mmm), I've had to find extra time. Erm, I think, I can given you my example, for instance, my patients very full, the outpatient clinic are booked six months ahead (yes), erm, unfortunately the only day when they could get all the professionals, well most of the professionals was, on this day of my outpatients, so I was very rushed (yes). And maybe I've been late (Psychiatrist) Indeed, another psychiatrist with some degree of modesty described how he saw his role with colleagues: "trying to relate to them best as I can to other team members, and probably taking on some of their expertise and offering that as part of my work". Thus, the channels of expertise are described here as acting in both directions - not entirely one way. The psychiatric staff identified their role as being a somewhat specialised one within the teams:

Erm, erm, I, I think a psychiatrist in, in this team ideally should be in a position to help with the biological, or the medical perspective, and help to take decisions from that regard. (Psychiatrist)

Indeed, rather than being described as affording leadership, other team members concurred in the view that psychiatrists have a role largely as a resource, rather than a source of direction:

Erm I, I can say to, you know, a consultant psychiatrist, or a colleague or a social worker or a psychologist, I can say erm, I think this, erm, do you agree? (yes). And they say yes that sounds like a good idea. And this, this is good isn't it? (CMHN) The non-medical team members tended, moreover, see psychiatrists as a highly specialised resource, with particular expertise and authority when it came to medication: he's there every Thursday ( $\mathrm{mmm})$. And if we need to look at medication, or things we've got worries about that we need a psychiatric view, er he's always there and we can talk to him about it. (Social Worker)

Sometimes the psychiatrist was merely one among many such resources:

I have this back up, back up if you like of a consultant psychiatrist and social workers and psychologists and all sorts of staff. (CMHN)

Thus, at least from the participants' accounts, a strong sense of medical dominance or direction is difficult to discern. Indeed, it is difficult to identify from this data a sense of 
decisions falling under the control of a 'dominant professional' (Griffiths, 1997). Indeed, our study takes its place amongst a number of voices in the literature who see power in health care as being much more diffuse than a straightforward notion of 'medical dominance' would suggest (Gastaldo \& Holmes, 1999; Samson, 1995). The sources of orderliness of our informants' working lives must be sought elsewhere. As we have suggested, based on the interview data, the governance of their conduct can perhaps best be seen in terms of their professionalised commitment to clients' welfare. Indeed, in a study of nurses' adoption of new technologies and recording systems by Fagerstrom and Engberg (1998), this was justified and rationalised as being an extension of their caring ideology. Staff then can be persuaded to do a great deal if it is believed to facilitate caring for clients. Deep management, then, is successful in that it mobilises these commitments.

\section{Irrelevant meetings and imaginary organisations}

A further clue as to where the sense of direction might come from can be deduced from the structure of the teams' meetings. These were typically two hours long and comprised a clinical section in which clients are discussed, and a business section in which minutes are read, team management is discussed, presentations may be given by outside experts and staff may be informed of courses or development opportunities. We might expect that those members with a larger stake in the running of the teams might have a correspondingly larger stake in the business sections of the meetings. However, there was, across the board, some frustration at the business sections. There were difficulties in finding enough business. For example, to one participant the business section was:

completely pointless, because somebody sits and reads all the minutes from the last sitting. Why are we reading all these, we've all had a copy, we've seen them, we know, you know, it's last week's meeting repeated again, in a sense (l: yes). (CMHN) Even the medical members, from whom historically has come the moral, managerial and clinical leadership in health care were just as likely as the others to find the business section onerous and not terribly useful:

The business section. Er, sometimes I find it doesn't really er, I can't really relate to 
that very much. (Psychiatrist)

On the other hand, there was some enthusiasm for the clinical sections. Their relative usefulness was aligned with notions of what the important matters of health care work involved:

Erm, I don't find the business section as, as useful as, as the clinical section (yeah), I mean the clinical section is what I do, it's talking about what, what I do, what other people are doing, that's the most important thing. (CMHN)

The irrelevance and distance of the steering group as a managerial force is mirrored by the apparent redundancy, lack of interest and irrelevance of the business section of meetings. Again, this reinforces the apparent absence of overt management. Even within the meetings there was a perceived lack of management and direction on the part of the meeting itself.

I: Right so a little bit more direction in, in planning who we're looking at and why, and when do [unclear]

$P$ : [and what we're trying to achieve as a group. Yeah a broader sense, sense of aims and objectives, what's the group been brought together to achieve? I mean it's (I: OK), obviously we've got a fair idea of what we've been brought together to achieve, but I think we need to step back from it and say (I: right) right what, let's be clear, OK, who's, who's going to be our priority (I: yes). Who are the people initially going to assess? Who are the most difficult people to engage with? Who are the least likely to accept service? Who are the most at risk? Getting those people.

I: So it's about priorities (P: yes), prioritising. (Social Worker)

This informant is alluding to ideas and concepts which are familiar from the point of view of management theory and yet he perceives that they are not being applied in the team itself, which is not so strategic as to formally implement the process of setting objectives. Again, we can see that a lack of apparent formal structure of management coexists with the participants' knowledge of what it could entail and what the process would be if it did exist. In this sense the management structures have been internalised, such that the members know what they think should be done but there is no external manifestation of this in the formal ceremonies of the organisation. The practitioners are 'self-producing' (Casey, 1999). This subjective organisation of structure has a relative autonomy from traditional pathways of influence which have been identified in health 
care, such as Traynor's (1996) identification of managerial inroads or Stein's (1967) 'doctor-nurse game'. Yet here the participants seem to be saying that this is not happening. Of course, the potential for structure of this kind is being oriented to and interactively discovered by the interviewer and participants, but this is not quite the same thing. There is a multiplicity of imaginary worlds of social structure, precisely because it is potential rather than ceremonially actualised.

Participants are developing a realm of discourse (or 'soul' in Rose's terms), which facilitates and substitutes the imaginary, potential structures where they are absent. They are thus able to conjure a representation of this desirable modus operandi which is relatively independent of their understanding of what the meetings actually contain. This solipsism is the most inward looking yet the most institutionally powerful regime. Even more than governing the soul it is influencing the very contents of the soul it regulates. Management, then, is relocated from the structure and activity of the organisation into people's subjective realm. Deep management is recursively forced back 'under the skull'. All the more so as participants imagine the kinds of managerial processes which would enable the caring role with clients to be supported.

The perceived irrelevance of the steering group, the valorisation of work with clients and the retreat into subjectivity when it comes to defining what a team is, help to facilitate the work of deep management. If participants describe their working lives in this way, they can be managed much more effectively with such a perceived lack of formal organisational structure to support or supervise them. The orderliness of their conduct, their caseload (perceived by some to be very high), their workload, and their continued diligence in attending meetings are vouchsafed more fully when they are reliant on themselves for guidance rather than their superiors. Thus, the perceived inaction of the steering group, rather than being a defect, can be seen in a more illuminating way. It is effectively blindsiding our informants and facilitating their management of themselves. The same can be said of the relative lack of evidence in our corpus of material for overt signs of medical dominance. As the medical staff are seen as specialist resources rather than sources of direction, they are not easily theorised as dominant. 
like other team members and have, in this context at least, been stripped of their usual authority and effectively been 'proletarianised' (Braverman, 1974; Garnham, 2000). This is in contrast to team members such as OTs, CMHNs, who as we have argued elsewhere (Brown, Crawford, \& Darongkamas, 2000) are developing a broader skill base and a more generic role. Perhaps we can see in our data further evidence of the 'fracturing of medical dominance' identified by Samson (1995) and the substitution of more entrepreneurial forms of workforce discipline where workers are encouraged explicitly through Government policy and by omission - to take responsibility for organising themselves.

\section{'Team' is a state of mind}

The retreat under the skull is even more complete than we have argued so far. The teams themselves are imaginary entities. When asked to comment on whether their teams really were teams in the full sense, participants overwhelmingly drew on subjective issues rather than matters of formal structure to make sense of the idea of a team. Those participants who felt the IMHTs were indeed teams emphasised the subjective aspects of being in a team and the sense of belonging. We shall argue that this solipsistic notion of what it is to be a team is facilitated by the lack of formally derived or defined criteria, rules and roles. For the teams in this study there was no common physical base or common structure of rules. Nevertheless, there is a sense of whether there was a team:

I: would you, could you call the Integrated Mental Health Team a team as such, do you think?

P: Well I say, I would call it a team, because we do work together. Erm, we have a willingness to work together ( $\mathrm{mmm}$ ), so I would actually call us the 'A team' (laughs).

I: The 'A team', excellent. (Mental health support worker) Whereas informants were divided as to whether they thought it was a team or not, inasmuch as they agreed that it was a team this took the form of a subjective sense. It was to do with the informal practices, sense of belonging and sharing a common philosophy. Those who said their IMHT was a team tended to qualify their answers and describe the lack of structure as something that needed explaining: 
I: could you call the Integrated Mental Health Team a team as such?

$\mathrm{P}:$ Well in the sense of the definition that we're working towards a common goal, and if the common goal is to provide a more co-ordinated service to the client at the end of the day, in that sense we are (Clinical Psychologist)

I think it's a team in a vacuum. And personally I feel it will benefit from clearer structures, and er, better agreed upon common policy and common goals.

(Psychiatrist)

Thus, in the view of this informant there was not the commonality of purpose, goals and policy that one would normally expect for a social entity to be called a team. Moreover, even though some other respondents felt that the IMHTs were indeed teams there were a number of features which they felt were missing, when compared to the use of the concept of team elsewhere in social life.

I: [ls it] to do with individuals' perceptions of being in a team, or is it something else?

$P$ : I think if you ask them they would say, well you obviously have done, I think they would say that they're are part of a team, yeah (I: yeah). But it's not like a football team, where the captain and everybody else is behind them, cause we ain't got a captain, (I: $\mathrm{mmm})$, and we're not all on the field at the same time (I: $\mathrm{mmm})$. (CMHN) There are two points of interest here. One is that the participant claims a generality for this feeling of being in a team, which in fact differs from some of his colleagues' perceptions that they are not in one. The other is that the notion of being in a team is qualified, inasmuch as it is not like being a football team and does not have the unity of action, propinquity or leadership that one might find in teams on the sports field.

I think you can call them a team if they've got a shared philosophy, they share, you know a mutual sort of goal. (Social Worker)

So although the sense in which IMHTs are teams is a subjective one, to the believer, there is a commonality about it - the belief must extend to fellow team members. This substitution of individual for collective forms of consciousness is an index of how far the process of individuation has extended. Being a team is about feeling like one. Team is a state of mind.

$P$ : it is a team, and I think it does think of itself as a team. Erm, it's, it's been my impression anyway and certainly through meeting as a team, it feels a team (Occupational Therapist) 
I: would you still maintain that the team is er erm, an accurate description of that organisation?

$P$ : It's really quite a difficult question to answer $(\mathrm{mmm})$ because I think we all think of ourselves as being a team ( $\mathrm{mmm})$. Erm, some, I mean even the people who perhaps don't actually work so much as a team, still think in terms of a team. It's very much about the perception of the team, rather than what's actually happening clinically which is what it's about ( $\mathrm{mmm}$ ). Does that make sense? (Occupational Therapist) There were a number of people in the study who did not think IMHTs were teams, in some cases because of factors in its physical organisation. For example, two geographical aspects were highlighted. One was that the teams had no common physical base. Informants' offices had remained scattered in a variety of premises and organisations: As one said "I think to be a real team, you do need to share a building." $(\mathrm{CMHN})$. The other geographical aspect was the anomalies over catchment areas and territories covered, such that clients might live in the territory covered by one team yet attend a hospital in an area covered by another, or that team members might have clients in an area outside the designated catchment area of their team.

Even so, it is clear that in the view of the participants the steering group is not hard at work resolving these issues. The laissez faire approach has again forced a reliance of team members on themselves, their own values and perceptions, and to a lesser extent on each other. The individuation of problems has the effect of making staff work harder. Simply finding rooms in which to meet requires time and phone calls, as does fitting existing caseloads around the timetabled meetings and Care Programme Approach events.

\section{In conclusion: the clinical governance of the soul}

In this study therefore we have discovered a realm of activity, and a way of forming accounts of what participants do, which is curiously at odds with a good deal of what has been written so far about the process of managing the delivery of care. Most observers of the health professions tend to emphasise the managerial activities of 'task assignment, problem solving and monitoring carried out by the first formal tier of the 
management hierarchy' (Tinsley \& Luck, 1998, p. 354). Indeed, the managerialist culture-shift in UK health care has sought to 'change the culture of the service to reflect the efficiency and quality standards of business' (Duggan, 1995). Given these observations we might expect to find conspicuous references to management in the transcripts as a force which initiated and monitored these programmes. However, there is very little other than the accounts of management being uninvolved which we have seen above. Whereas their caring work is broadly in agreement with health policy in the UK, this is not implemented by a formal tier of management above them. Likewise, our participants provided us with little conspicuous evidence that their working lives could easily be understood in terms of traditional medical dominance.

In some organisational literature there is a good deal of emphasis on the value of positive employee attitudes and a sense of alignment with the organisation's core values (Meglino, Ravlin, \& Adkins, 1989; Posner, 1992; Syrett et al., 1997). The sense of shared meaning with colleagues and emotional attachment to core values and philosophies has been linked to positive work attitudes and enhanced work performance. It is said that it is beneficial for the individual and the organisation if the individual is 'psychologically present' in his or her work (Kahn, 1992). These ideas appear in many textbooks on human resources. However, our informants have had to work to achieve these ideals for themselves. Whereas opinion is divided as to whether the workforce is indeed a team, we can see that for the believers, 'we all think of ourselves as being a team'. Individual team members then are hard at work creating for themselves the sense of membership and belonging which has been highlighted by students of human resources. The 'cunning of democracy' (McClintock, 1995) as applied to management has been to internalise these processes in the discourse of a substantial proportion of the practitioners. This then is at the core of what we call deep management. The rebirth of social concepts such as teams as if they were matters of subjective feeling (Casey, 1999), the recursive focus on the individual practitioner as the solution to the organisation's problems, with a precise, self-managing way of relating to themselves and their future creates a regime of personhood and a regime of organisational truth (Casey, 1999; Rose, 1997). Thus, we have seen evidence in this health service organisation for a process which scholars of the commercial 
organisational sector have also begun to detect. McKinlay and Taylor (1998, pp. 190-191) say their observations suggest that 'the high involvement workplace aims not at the managerial choreography of bodies but constant improvisation in work organisation and the unobtrusive orchestration of employee values'. As Boyne (2000, p. 294) adds, it is as if the organisation is using 'every worker as an autochthonous surveillance point' which accomplishes the microscopic policing of members' subjectivity. In our study then, it is to these possibilities we turn given that there are no clear pathways of managerial or medical dominance in our participants' accounts.

Perhaps we might see similar kinds of deep management at work in other human service occupations. The preconditions may well turn out to involve a close fit between the professional ideology of the group concerned and a strong client service ethic, combined with an absence of conspicuous, directive, first-tier line management. Professionals who are simply 'left to get on with it' have, in a sense, been managed most effectively because they have absorbed sufficient of the caring ideology to construct a way of driving themselves on with the task. Nursing especially has little tradition of autonomous, directive management (Fedoruk \& Pincombe, 2000). Moreover, the reorganisation of health care at both a national and local level is apt to make staff cling more tenaciously to what they see as threatened professional identities (MacDonald, 1999). Hence, the uncertainty, lack of direction and recent organisational changes may have facilitated participant's reliance on their caring work and caring identities. A strong caring identity may be a necessary but insufficient condition for deep management to take hold. It may also require the apparent absence of formal leadership in order for the personnel to develop these capacities as a corollary of the individualised responsibility to care for one's clients. In Rose's (2000) account of the spread of psychological ways of understanding the human condition, there are few formal pathways of influence but the psychological project nevertheless became very pervasive. Likewise, in the absence of formal control, a kind of autopoesis has re-engineered the practitioners' souls and working practices.

Given the concentration of so many other authors on the friction between health care practitioners and assertive managerial styles, we were surprised to find so little friction 
here. Indeed, the steering group was so inert that it is difficult to imagine friction taking place at all. Whether our teams were unique is a matter for speculation but in some literature on nursing management this sense of a managerial and supervisory vacuum is beginning to emerge (Aitken et al., 2001; Kelly, Long, \& McKenna, 2001). Indeed, there are even some suggestions that nurses should equip themselves to be promoted into this gap left by the retreat of management (Truman, 2001). Our participants' experience then may represent one fragment of a much larger mosaic.

Returning to the question of plucky practitioners resisting managerial inroads, this recollects other examples of how oppositional cultures effectively promote a governmental purpose in occupational settings. Willis's (1977) well-known examples of how youths' oppositional culture in school actually facilitates their fitting in with workplace culture later in life, has been multiplied by other students of organisations (e.g. Willmott, 1993). The distance our informants feel from the steering group and its 'hot air' means that their professional identities are moulded ever more effectively. The autonomous, productive subjectivity of the enterprising professional has become an ever more central resource in the health service. The 'self-regulating capacities' (Miller \& Rose, 1990) are both personally seductive and economically desirable. Moreover, these self-regulating, self-reliant identities are facilitated by this hands-off management style and resonate with notions of the self-reliant, self-educating, evidence seeking professional incorporated within the clinical governance initiative. The process is a kind of management rather than merely the acting-out of a predefined caring ideology because it is a flexible and resourceful implementation of healthcare work which brings it into alignment with Government policy. On seeing the letters 'NSF' in ball-point on the back of an occupational therapist's hand one of us (BB) inquired what it meant 'National Schizophrenia Fellowship?' - and received the reply 'No, National Service Framework' which she was intending to consult. The frenetic routine of seeing clients is curiously reminiscent of the UK National Service Framework's foregrounding of client's needs and its recommendation of ensuring regular, timely contact between staff and clients especially if clients are likely to pose a 'risk to themselves or others' (Department of Health, 1999b, p. 151). 
The value participants attach to working with clients has effected the seepage of self-management into the professional culture of these participants. In the absence of formal support and guidance from their senior colleagues they have effectively become self-regulating so that professionalism itself has become a disciplinary mechanism (Fournier, 1999). Thus, much as managers in commercial life have been encouraged to abandon the role of controller and become empowering facilitators of staff, where staff themselves are encouraged to take on the mission of enterprise, it is as if a similar process has happened serendipitously here. The marginality of the steering group to our informants' working lives has deepened its managerial grasp.

\section{Acknowledgements}

The authors gratefully acknowledge the help of Jurai Darongkamas, Clinical Psychologist, and Amanda Knight and Sue Bickerton, researchers, who helped formulate and implement the broader programme of work of which this study formed a part.

\section{References}

Aitken, L. H., Clarke, S. P., Sloane, D. M., Sochalski, J. A., Buse, R., Clarke, H., Giovannetti, P., Hunt, J., Rafferty, A. M., \& Shamian, J. (2001). Nurses reports of hospital care in five countries: The ways in which nurses work is structured have left nurses among the least satisfied workers, and the problem is getting worse. Health Affairs, 20(3), 43-53.

Barrett, R., \& Good, B. J. (1996). The psychiatric team and the social definition of schizophrenia.. Cambridge: Cambridge University Press.

Berg, M. (1996). Practices of reading and writing: The constitutive role of the patient record in medical work. Sociology of Health and IIIness, 18(4), 499-524.

Berg, M., \& Bowker, G. (1997). The multiple bodies of the medical record: Towards a sociology of artefact. The Sociological Quarterly, 38(3), 513-537.

Berger, P., \& Luckmann, J. (1966). The social construction of reality. Harmondsworth: Penguin.

Boyne, R. (2000). Post-panopticism. Economy and Society, 29(2), 285-307.

Braverman, H. (1974). Labour and monopoly capital in the twentieth century. New York: 
Monthly Review Press.

Brown, P. (1990). The name game: Towards sociology of diagnosis. Journal of Mind and Behaviour, 11(4), 385-406.

Brown, B., Crawford, P., \& Darongkamas, J. (2000). Blurred roles and permeable boundaries: The experience of multidisciplinary working in community mental health. Health and Social Care in the Community, 6(6), 425-435.

Casey, C. (1999). Come join our family: Discipline and integration in corporate organisational culture. Human Relations, 52(2), 155-178.

Castledine, G. (2000). Clinical governance: Opportunity for nurses? British Journal of Nursing, 9(10), 670.

Department of Health (1997). The new NHS: Modern, dependable. London: The Stationary Office.

Department of Health. (1998). A first class service: Quality in the New NHS. London: Department of Health.

Department of Health. (1999a). Making a difference, strengthening the nursing, midwifery and health visiting contribution to health and health care. London: Department of Health.

Department of Health. (1999b). A national service framework for mental health. London: Department of Health.

Department of Health. (2000). Mental health national service framework workforce planning education and training: Interim report by the workforce action team. London: Department of Health.

Du Gay, P. (1997). Production of culture/ cultures of production. London: Sage in collaboration with the Open University Press.

Duggan, M. (1995). Primary health care - a prognosis.. London: Institute of Public Policy Research.

Edwards, D., \& Potter, J. (1992). Discursive psychology. London: Sage.

Elcoat, E. (2000). Clinical governance in action. Professional Nurse, 15(10), 622-623. Fagerstrom, L., \& Engberg, S. (1998). Measuring the unmeasurable: A caring science perspective on patient classification. Journal of Nursing Management, 6(3), 165-172. Fedoruk, M., \& Pincombe, J. (2000). The nurse executive: Challenges for the $21 \mathrm{st}$ century. Journal of Nursing Management, 8(1), 13-20. 
Foucault, M. (1977). Discipline and punish: The birth of the prison (Trans. by Sheridan, A.). Harmondsworth: Penguin.

Fournier, V. (1999). The appeal to professionalism as a disciplinary mechanism. The Sociological Review, 47, 280-307.

Garnham, N. (2000). Information society as theory or ideology: A critical perspective on technology, education and employment in the information age. Information, Communication and Society, 3(2), 203-228.

Garvin, J. N. (1997). Nursing ideology and the 'generic career'. Journal of Advanced Nursing, 26, 62-697.

Gastaldo, D., \& Holmes, D. (1999). Foucault and nursing: A history of the present. Nursing Inquiry, 6, 231-240.

Gervais, M. -C., Merant, N., \& Penn, G. (1999). Making sense of absence: Towards a typology of absence in social representations theory and research. Journal for the Theory of Social Behaviour, 29(4), 419-444.

Glaser, B. G., \& Strauss, A. (1967). The discovery of grounded theory. New York: Aldine Publishing Co.

Grey, C. (1994). Career as a project of the self and labour process discipline. Sociology, 28(2), 479-497.

Griffiths, L. (1997). Accomplishing team: Teamwork and categorisation in two community mental health teams. The Sociological Review, 45(1), 59-78.

Harvey, G. (1999). A Nursing perspective on clinical governance: Policy, principles and priorities. Journal of Clinical Excellence, 1, 167-174.

Hatchuel, A. (1999). The Foucaldian detour: A rebirth of organisation theory? Human Relations, 32(4), 507-519.

Hicks, C. (1998). Evidence-based care in nursing: Reforms versus research, rhetoric versus reality. Health Services Management Research, 11, 246-254.

Kahn, W. A. (1992). To be fully there: Psychological presence at work. Human Relations, 45(4), 321-348.

Kelly, B., Long, A., \& McKenna, H. (2001). A survey of community mental health nurses' perception of clinical, supervision in Northern Ireland. Journal of Psychiatric and Mental Health Nursing, 8(1), 33-44.

Kings Fund (1997). Community care debates: The future organisation of community 
care options for the integration of health and social care. London: The Kings Fund. Kunda, G. (1991). Ritual and the management of corporate culture: A critical perspective. Paper presented at the Eighth International Standing Conference on Organisational Symbolism, Copenhagen, June 1991.

MacDonald, G. (1999). Evidence based social care: Wheels off the runway. Public Money and Management, 19(1), 25-32.

Mathis, R. L., \& Jackson, J. H. (1994). Human resource management. ((7th ed.)). New York:West Publishing Co.

McClintock, B. (1995). The cunning of democracy. London: Routledge.

McKinlay, A., \& Starkey, K. (1998). Foucault, management and organisation theory. London: Sage.

McKinlay, A., \& Taylor, P. (1998). Through the looking glass: Foucault and the politics of production. In A. McKinlay, \& K. Starkey (Eds.), Foucault, management and organisation theory. London: Sage.

Meglino, B., Ravlin, E., \& Adkins, C. (1989). A work values approach to corporate culture: A field test of the value congruent process and its relationship to individual outcomes. Journal of Applied Psychology, 74(3), 424-432.

Miller, P., \& Rose, N. (1990/1997). Governing economic life. In: Du Gay, P. (Ed.), Production of culture/cultures of production. London: Sage in collaboration with the Open University Press.

Moore, D., \& Valverde, M. (2000). Maidens at risk: 'Date rape drugs' and the formation of hybrid risk knowledges. Economy and Society, 29(4), 514-531.

Morrall, P. A. (1998). Mental health nursing and social control. London: Whurr Publishers Ltd.

Murdach, A. D. (1995). Clinical practice and heuristic reasoning. Social Work, 40(6), 752-758.

NHS Executive. (1999). Clinical governance - quality in the new NHS. London: Department of Health.

Norman, I. J., \& Peck, E. (1999). Working together in adult community mental health teams: An interprofessional dialogue. Journal of Mental Health, 8(3), 217-230.

Novas, C., \& Rose, N. (2000). Genetic risk and the birth of the somatic individual. Economy and Society, 29(4), 485-513. 
Onyett, S., \& Ford, R. (1996). Multidisciplinary community teams: Where is the wreckage? Journal of Mental Health, 5(1), 47-55.

Ovretveit, J. (1993). Co-ordinating community care: Multidisciplinary teams and care management. Buckingham: Open University Press.

Patmore, D., \& Weaver, T. (1991). Missing the CMHC bus. Nursing Times, 87(17), 32-34.

Pestello, F. (1993). Discounting. Journal of Contemporary Ethnography, 20(1), 26-46.

Piper, A. (2000). Some have credit cards and others have giro cheques: 'Individuals' and 'people' as lifelong learners in late modernity. Discourse and Society, 11(4), 515-542.

Posner, B. (1992). Person-organisation values congruence: Support for individual differences as a moderating influence. Human Relations, 45(4), 351-361.

Potter, J., \& Wetherell, M. (1987). Discourse and social psychology. London: Sage. Rose, N. (1990). Governing the soul.. London: Routledge.

Rose, N. (1997). Assembling the modern self. In R. Porter (Ed.), Re-writing the self: Histories from the Renaissance to the present. London: Routledge.

Rose, N. (2000). Governing the soul: The shaping of the private self (2nd ed.). London: Routledge.

Samson, C. (1995). The fracturing of medical dominance in British psychiatry. Sociology of Health and IIIness, 17(2), 245-268.

Snelgrove, S., \& Hughes, D. (2000). Interprofessional relations between doctors and nurses: Perspectives from south Wales. Journal of Advanced Nursing, 31(3), 661-667. Speer, S. A., \& Potter, J. (2000). The management of heterosexist talk: Conversational resources and prejudiced claims. Discourse and Society, 11(4), 543-572.

Stein, L. I. (1992). On the abolishment of the case manager. Health Affairs, 11(4), 172-177.

Stein, L. T. (1967). The doctor nurse game. Archives of General Psychiatry, 16, 699-703.

Strauss, A. L., \& Corbin, J. (1998). Basics of qualitative research: Techniques and procedures for developing grounded theory (2nd ed.). Thousand Oaks, CA: Sage. Syrett, V., Jones, M., \& Sercombe, N. (1997). Implementing community care: The congruence of manager and practitioner cultures. Social Work and Social Sciences 
Review, 7(3), 154-169.

Tinsley, R. N., \& Luck, M. (1998). Organising community nursing: An exploratory study. Health and Social Care in the Community, 6(5), 353-360.

Traynor, M. (1996). A literary approach to managerial discourse after the NHS reforms. Sociology of Health and IIIness, 18(3), 315-340.

Truman, P. (2001). The only way is up nurses who aspire to get management positions. Nursing Standard, 15(38), 20.

Willis, P. (1977). Learning to labour: How working class kids working class jobs. London: Saxon House.

Wells, J. S. G. (1997). Priorities 'street level bureaucracy' and the community mental health team. Health and Social Care in the Community, 5(5), 333-342.

Willmott, H. (1993). Strength is ignorance; slavery is freedom: Managing culture in modern organisations. Journal of Management Studies, 30(4), 515-552. 